\title{
ENCUENTRO DE REVISTAS EUROPEAS DE ARABISMO
}

Por

MÍKEL DE EPALZA

El 18 de abril de 1989, se reunieron en la Universidad de Aix-en-Provence (Francia) los representantes de tres revistas científicas europeas de estudios árabes: PierreRobert Baduel, por la REVUE DU MONDE MUSULMAN ET DE LA MÉDITERRANÉE (Aix-en-Provence), Salvatore Bono, por ÁFRICA (Roma) y Míkel de Epalza, por SHARQ AL-ANDALUS. ESTUDIOS ÁRABES (Alicante). El 17 habian presentado las tres revistas en Toulon, en una mesa redonda con otras revistas con vocación internacional mediterránea (SUD, de literatura; AQUO D'AQUI, provenzalista y lenguadociana), con un debate muy animado sobre el papel de las revistas culturales frente a los libros, las revistas de información general y la prensa diaria, escrita, oral y televisiva.

El día 18, se efectuó la presentación de las revistas ÁFRICA y SHARQ ALANDALUS, en la librería "Vents du Sud» de Aix-en-Provence, ante un público de unas 50 personas, en su mayoría profesores e investigadores de las Facultades de Letras y Derecho y del Centro de Investigación Maison de la Méditerranée, de la Universidad de Provenza.

El Dr. Epalza presentó a SHARQ AL-ANDALUS y a sus publicaciones periódicas asociadas (ARABISMO ALICANTINO, de información regional; ALJAMIA, con Oviedo, para bibliografía arábigo-románica; AL-MASAQ, de Leeds, para el mundo anglosajón, sobre relaciones interculturales árabe-mediterráneas; DIRASAT ANDALUSIYYA, de Túnez, para textos en árabe sobre Al-Andalus). También presentó a revistas científicas en las que profesores de Alicante están en los consejos de redacción: AL-QANTARA (Madrid, Dra. Rubiera), AWRAQ (Madrid, Dres. Epalza y Villegas), BOLETÍN DE ASOCIACIÓN ESPAÑOLA DE ORIENTALISTAS (Madrid, Dra. Rubiera), ISLAMOCHRISTIANA (Roma, Dr. Epalza). También presentó a atras revistas científicas españolas de estudios árabes e islámicos: MISCELÁNEA DE ESTUDIOS ÁRABES, CUADERNOS DE LA ALHAMBRA, CUADERNOS DE HISTORIA DEL IS- 
LAM, ANDALUCIA ISLAMICA (Granada), REVISTA DEL INSTITUTO EGIPCIO DE ESTUDIOS ISLÁMICOS (Madrid), encuadrándolas todas ellas en el marco de los estudios árabes en España. También presentó otras publicaciones arabísticas de la Universidad de Alicante (ibros, congresos, misceláneas, bibliografías).

Finalmente, y por acuerdo previo con los Dres. Baduel y Bono, introdujo el tema de un actual y futuro «espacio europeo» de las revistas de estudios árabes e islámicos.

El largo y animadísimo debate que siguió puso de relieve, aparte de los problemas comunes a estas publicaciones cientificas minoritarias y sólo parcialmente comercializadas, algunas necesidades nuevas de colaboración, a nivel europeo, además de las deseables colaboraciones con revistas árabes:

$\left.1 .{ }^{\circ}\right)$ Reuniones regulares de directores de las 15020 revistas europeo-occidentales de estudios árabes, para programar colaboraciones.

$\left.2 .^{\circ}\right)$ Superar la actual colaboración internacional de meros intercambios de publicaciones o participación de investigadores de otros países, con una programación de números especializados en algunos temas, mayor especialización de cada revista y presentaciones bibliográficas mutuas.

$\left.3 .{ }^{\circ}\right)$ Preparar la publicación de una revista de estudios árabes a nivel europeo.

$\left.4 .^{\circ}\right)$ Equilibrar con resúmenes en otras lenguas la necesaria utilización de las lenguas propias europeas.

Las aportaciones italiana, francesa y española coincidieron, programáticamente, en que la investigación de nuestras revistas no tiene sólo que considerar los estudios árabes e islámicos como temas de investigación en sí, en su alejamiento oriental geográfico y social, sino también como parte de los estudios europeos sobre la propia Europa (su pasado árabe, sus poblaciones árabe-islámicas actuales, sus relaciones históricas y presentes bilaterales con el mundo árabe-islámico, etc.). La constitución de una red de esos estudios, a nivel de los 12 paises del MCE, en los que los investigadores, lośr recursos bibliográficos, los profesores y los estudiantes no se sientan extranjeros y sí colaboradores complementarios en una tarea plural, puede ser una de las tareas prioritarias de estas revistas cientificas. 